\title{
Feiras livres de Pelotas/RS: uma análise sob a perspectiva da Segurança Alimentar e Nutricional
}

\author{
Street market in the south of Brazil: Food and Nutrition Security under perspective
}

\author{
Camila Irigonhé Ramos \\ Denise Petrucci Gigante
}

Eliana Gomes Bender

Inaê Dutra Valério

Universidade Federal de Pelotas - Pelotas - Rio Grande Do Sul - Brasil

\begin{abstract}
Resumo: Dado a importância de se conhecer a disponibilidade e o consumo de frutas, legumes e vegetais, o presente trabalho objetivou caracterizar as feiraslivres, os feirantes e os alimentos comercializados na cidade de Pelotas/RS. Tratase de um estudo transversal realizados com todos os feirantes que comercializavam frutas, vegetais e/ou verduras na cidade de Pelotas. A coleta ocorreu entre fevereiro a agosto de 2014 e incluiu produtores e revendedores advindos de feiras convencionais e ecológicas. Dos 37 locais de feiras, 34 eram convencionais (92\%) e três (8\%) eram ecológicas. Quanto ao local de permanência das feiras, 80\% se dava na zona central da cidade (81\%). Em relação aos 125 comercializantes participantes, a maioria era do sexo masculino (65\%), com idade maior que 60 anos (26\%), cor de pele branca (98\%) e com baixo nível escolar (entre 5 a 8 anos) (44\%). A maior parte dos legumes e verduras, como alface (34\%) e abóbora (29\%), eram produzida pelos feirantes, todavia alimentos consumidos no dia a dia, como batata rosa (34\%) e cebola (34\%), eram, na maior parte dos casos, revendidos. Constatou-se que a maior disponibilidade dos produtos advindos das feiras se dá na zona central da cidade, distanciando o acesso ao produto da população que vive em distritos mais afastados. É preciso que ações legislativas por parte do município sejam feitas para incentivar a manutenção, a permanência e a propagação das feiras livres ao redor da cidade.
\end{abstract}

Palavras-chave: Segurança alimentar e Nutricional. Agricultura. Comércio.

Abstract: Given the importance of knowing the availability and consumption of fruits vegetables and vegetables, the present study aimed to characterize the street market the market workers and the foods commercialized at city of Pelotas in the South of Brazil. A cross-sectional study of all the marketers selling fruits, vegetables or vegetables in the city of Pelotas were enrolled between February and August of 2014 and included producers and resellers from conventional and organic fairs. Of the total of 37 fairgrounds included, 34 were conventional (92\%) and three (8\%) were ecological. About de location, $80 \%$ was in the central part of the city (81\%). Among the 125 participating marketers, the majority were male $(65 \%)$, older than 60 years $(26 \%)$, white skin color $(98 \%)$ and low school level (between 5 and 8 years old) (44\%). Most of the vegetables, such as lettuce (34\%) and pumpkin (29\%), were produced by farmers, but foods consumed daily, such as potatoes (34\%) and onions (34\%) were, in most cases, resold. It was verified that the greater availability of the products coming from the fairs occurs in the central zone of the city, distancing the access to the product of the population that lives in more distant districts. It is necessary that legislative actions by the municipality are made to encourage the maintenance, the permanence and the propagation of the free fairs around the city.

Keywords: Food and Nutrition Security. Agriculture. Commerce. 


\section{Introdução}

A Segurança Alimentar e Nutricional (SAN) é um conceito interdisciplinar, que envolve, principalmente, a realização de práticas alimentares voltadas à participação popular e à promoção da saúde (Kepple; Segall-Corrêa,2011) . As iniciativas voltadas à discussão desse tema são recentes. Em 2006, a luta pela SAN obteve, no Brasil, uma conquista significativa em âmbito institucional. A promulgação da Lei Orgânica de Segurança Alimentar e Nutricional (LOSAN) - Lei no. 11.346 - e a criação do Sistema Nacional de Segurança Alimentar e Nutricional (SISAN) levaram a discussão a outro patamar (BRASIL, 2006). Além disso, em 2010, o direito à alimentação passou a ser respaldado pela Constituição, por meio da Emenda Constitucional $\mathbf{n}^{\circ}$ 64, de 2010. Desde então, conforme aponta Maluf, não se pôde mais ignorar a necessidade de pensar essa questão no domínio das políticas públicas (MALUF,2009).

Diante desses avanços, ressalta-se a importância do acompanhamento das políticas e ações de SAN. Embora o monitoramento em questão esteja sendo pensado desde a Il Conferência de SAN (2004), foi no ano de 2010, por meio do Decreto $n^{\circ} 7.272,-0$ qual regulamenta a Lei no 11.346 e estabelece os parâmetros para a elaboração do Plano Nacional de Segurança Alimentar e Nutricional (PLANSAN) - que ficou firmado nas diretrizes da Política Nacional de Segurança Alimentar e Nutricional (PNSAN) o estímulo ao abastecimento, principalmente de base agroecológica, e o monitoramento da realização do direito humano à alimentação adequada (DHAA) (BRASIL, 2010).

Neste mesmo ano, o Conselho Nacional de Segurança Alimentar e Nutricional (CONSEA) lançou o relatório : A Segurança Alimentar e Nutricional e o Direito Humano à Alimentação Adequada Indicadores e Monitoramento, o qual contém sete dimensões de observação da SAN. No que tange o interesse do presente estudo, é importante destacar a primeira dimensão, que aborda o monitoramento da produção e disponibilidade de alimento (CONSEA,
2010). Neste item, aponta-se a produção e disponibilidade de frutas, legumes e verduras (FLV), uma vez que tais alimentos fazem parte de uma alimentação saudável.

Ao incentivar o consumo de FLV, as políticas públicas têm agido de forma estratégica na promoção da SAN e na garantia do DHAA. De acordo com Pinheiro e Gentil (2005), ao estarem diretamente relacionados a questões de saúde pública, tais alimentos envolvem, principalmente, políticas de abastecimento e mantém o foco na agricultura familiar, no acesso e na educação para uma alimentação saudável. Para analisar o referido processo, no entanto, é preciso dispor-se à inserção neste universo, de modo a dialogar com seus protagonistas. $O$ consumo de FLV é apenas um dos estágios dessa cadeia de relações, que apenas se realiza a partir da produção e comercialização de tal grupo de alimento (PINHEIRO;GENTIL, 2005) .

É indispensável, portanto, considerar os aspectos biológicos, culturais, ambientais e econômicos que permeiam o cultivo, a comercialização e a escolha da ingestão de FLV. Do ponto de vista histórico, as primeiras formas de comercialização destes produtos remetem às feiras livres (PANELLIMARTINS; SANTOS; ASSIS, 2008). Esses espaços podem ser considerados potenciais modificadores da forma de se alimentar do povo brasileiro. Tal entendimento parece ser o que norteia as políticas públicas, uma vez que uma das ações da publicação do Ministério da Saúde, lançada há cinco anos, consiste em "incentivar a consolidação das feiras locais, como instrumento de melhoria para a seleção e aquisição de alimentos saudáveis"(BRASIL,2009,p. 7).

Desse modo, as feiras podem constituir-se em um canal de reaproximação entre produtor e consumidor, associada à redescoberta de um sistema alimentar influenciado e enfraquecido por pelo menos dois acontecimentos:

1) $\mathrm{Na}$ década de 70 , com a Revolução Verde, ocorre a adoção de um pacote tecnológico e a utilização intensa de agrotóxicos, adubos químicos e outros fertilizantes. Além disso, registra-se o aumento das despesas com o cultivo e o endividamento dos 
pequenos agricultores, o crescimento da dependência dos países, do mercado e da lucratividade das grandes empresas de insumos agrícolas (MALUF; MENEZES, 2000).

2) A padronização da alimentação, em um contexto de industrialização da comida, que ocasionou à perda de características próprias das culturas alimentares. Esse processo fez com que os consumidores passassem a conhecer apenas 0 produto final que acabam por ingerir (CONTRERAS; GRACIA ,2011).

Assim, ao refletir sobre a SAN, deve-se analisar a produção, a disponibilidade e o consumo de FLV inseridas no contexto de um sistema alimentar complexo. Esse sistema pode ser entendido como um conjunto de caminhos por onde o alimento transita da produção ao consumo. Nesse percurso, existem atores sociais que contribuem para a fabricação, transformação e distribuição dos produtos alimentares e que agregam ao alimento conhecimentos e valores que contribuem para a tomada de decisão sobre por que, como, quando e com quem consumir determinado tipo de alimento (CONTRERAS; GRACIA ,2011).

Diante do exposto, ressalta-se que o presente estudo teve por objetivo caracterizar as feiras-livres, os feirantes e os alimentos comercializados, de Pelotas/RS.

\section{Materiais e Métodos}

A pesquisa de campo foi realizada no município de Pelotas/RS, durante o período de dezembro de 2013 a agosto de 2014. Trata-se de um estudo descritivo, de corte transversal. Para a coleta dos dados elaborou-se e utilizou-se - após estudo piloto um questionário com questões fechadas, o qual foi aplicado ao proprietário de cada banca (conforme indicação dos próprios feirantes ou por meio do cadastro dos feirantes na Prefeitura).

Foram incluídos no estudo todos os feirantes que comercializavam FLV e aceitaram participar da investigação. Em fevereiro de 2014 foram selecionadas e treinadas 12 voluntárias (graduandas de nutrição) e, neste mesmo mês, teve início a coleta de dados. Para iniciar a aplicação dos questionários foi tomada para orientação uma lista dos locais das feiras, disponibilizada em agosto de 2013 por um dos funcionários da administração do município, lotado na Secretaria Municipal de Obras e Serviços Urbanos (SOSU). Para não gerar inconvenientes a feirantes e fregueses, a aplicação dos questionários ocorreu sempre no início ou final do turno de comercialização dos alimentos. Em maio de 2014, ainda durante a aplicação dos questionários, foi obtida, junto a outro funcionário da Prefeitura Municipal de Pelotas, a informação de que o município possuía em torno de 39 locais de feira. Segundo esse informante, somavamse, à época, 176 feirantes convencionais cadastrados.

No município existem dois tipos de feiras convencionais e ecológicas-, que são nomeadas (pelos feirantes e pela gestão municipal) de acordo com o modo como se realiza a produção de alimentos. Nas feiras convencionais, os alimentos são comercializados por produtores e/ou revendedores e, na produção das FLV, não há restrição quanto à utilização de insumos. Neste local são comercializadas FLV que são produzidas em todo o país. Já nas feiras ecológicas, os alimentos são vendidos somente por produtores e produzidos regionalmente sem utilização de agroquímicos.

No questionário foram incluídas variáveis demográficas, socioeconômicas, relacionadas ao trabalho dos feirantes e às FLV. Compõem o primeiro grupo as seguintes variáveis: sexo; idade em anos completos; estado civil (solteiro, divorciado, separado, viúvo, casado ou com companheiro); cor da pele, autoreferida, conforme classificação do IBGE (as opções eram lidas para o feirante); número de filhos; e local de moradia.

No que tange às variáveis socioeconômicas, considerou-se: escolaridade em anos completos de estudo; número de pessoas que moram na casa; e renda mensal de todos os moradores do domicílio do feirante. Quanto às relacionadas ao trabalho, apreciouse: o tipo de feirante (se produtor, revendedor ou ambos); tempo de trabalho em anos completos; local de produção ou aquisição das FLV; condição de cooperativado e características das outras pessoas que trabalham com o feirante. Por fim, em relação às 
variáveis relacionadas aos alimentos comercializados, analisou-se: os tipos de alimentos produzidos e/ou revendidos; o tipo de produção; e o local de comercialização.

Para a análise dos dados foi elaborado um banco de dados no programa Epidata 3.1, onde as informações foram inseridas com dupla digitação trabalho operacionalizado por diferentes digitadores. A análise descritiva dos dados foi realizada por meio de distribuição de frequências no programa Stata versão 12.0 .

A participação de todos os feirantes foi voluntária e a aplicação do questionário ocorreu somente após o entendimento e a assinatura do Termo de Consentimento Livre e Esclarecido. O presente estudo faz parte da dissertação de Mestrado em Nutrição e Alimentos da autora, na Faculdade de Nutrição da Universidade Federal de Pelotas, e foi aprovado pelo Comitê de Ética em Pesquisa da Faculdade de Medicina/UFPel, com o número do parecer 532.894 .

\section{Resultados}

Foram localizados 37 dos 39 pontos de feira onde ocorria a comercialização de FLV. Um local não foi encontrado mesmo após quatro visitas ao endereço informado e cadastrado na Prefeitura; e, o outro, que também não foi localizado, segundo o relato de alguns feirantes "não existiria mais". Das 37 feiras pesquisadas, 34 eram convencionais (92\%), onde eram comercializados, com raras exceções, alimentos de produção convencional (Tabela1).
Tabela 1- Características do trabalho dos feirantes nas feiras-livre da cidade de Pelotas/2014

\begin{tabular}{|c|c|}
\hline Variável & $\begin{array}{c}\text { Frequência } \\
\text { n (\%) }\end{array}$ \\
\hline \multicolumn{2}{|l|}{ Tipo de feirante } \\
\hline Somente produtor & $27(23,0)$ \\
\hline Somente revendedor & $47(39,8)$ \\
\hline Produtor e revendedor & $44(37,2)$ \\
\hline \multicolumn{2}{|l|}{ Tempo que é produtora } \\
\hline 1-6 anos & $6(11,3)$ \\
\hline $7-10$ anos & $4(2,8)$ \\
\hline 11 ou mais anos & $61(85,9)$ \\
\hline \multicolumn{2}{|l|}{ Tempo que é revendedorb } \\
\hline 1-6 anos & $20(22,0)$ \\
\hline $7-10$ anos & $5(5,5)$ \\
\hline 11 ou mais anos & $66(72,5)$ \\
\hline \multicolumn{2}{|l|}{ Tempo que é feirante (em anos) ${ }^{c}$} \\
\hline$<1$ & $7(6,0)$ \\
\hline $1-10$ & $26(22,6)$ \\
\hline $11-20$ & $27(23,5)$ \\
\hline $21-30$ & $34(29,6)$ \\
\hline $31-40$ & $13(11,3)$ \\
\hline $41-50$ & $8(7,0)$ \\
\hline \multicolumn{2}{|l|}{ Produz no local onde mora ${ }^{a}$} \\
\hline Sim & $69(58,0)$ \\
\hline Não & $2(2,0)$ \\
\hline \multicolumn{2}{|l|}{ revenda $^{b}$} \\
\hline CEASA de Pelotas & $69(75,8)$ \\
\hline Pequenos produtores da região & $22(24,2)$ \\
\hline
\end{tabular}

a71 feirantes produtores ou produtores e revendedores ${ }^{\mathrm{b}}$ considerando 91 feirantes ${ }^{\mathrm{c}} 3$ missing

Já com relação às feiras ecológicas, foi possível identificar em apenas três pontos. O predomínio de feiras, tanto convencionais quanto orgânicas, se dá na zona central da cidade (81\%). Na presente pesquisa, a maioria dos feirantes (81\%) relatou não ter participado da escolha do local da feira, porém, mais de $90 \%$ desses afirmou estar satisfeito com a localização da(s) feira(s) em que trabalha. Alguns ainda fizeram reclamações sobre a falta de manutenção das ruas. Grande parte (56\%) dos comerciantes comentou que há boa divulgação sobre 
os locais das feiras. Por outro lado, o restante considerou que não há investimento por parte da Prefeitura sobre a divulgação desses locais, sugerindo que os frequentadores são aqueles que já sabem onde a feira está localizada.

Durante o período de aplicação dos questionários foram encontrados 157 dos 176 feirantes cadastrados na prefeitura. Dentre os comerciantes localizados, 125 comercializavam FLV, sendo que 118 aceitaram participar da pesquisa. Dois não foram encontrados e cinco recusaram-se a participar (todas as recusas ocorreram nas feiras convencionais). Obteve-se, assim, uma taxa de resposta da população alvo deste estudo de $94 \%$.

Em relação aos resultados socioeconômicos, apresentados na Tabela 2, A maior parte dos feirantes que responderam ao questionário é do sexo masculino (65\%), com idade maior que 60 anos, e cor de pele branca.
Tabela 2 - Características sociodemográficas dos feirantes da cidade de Pelotas/2014

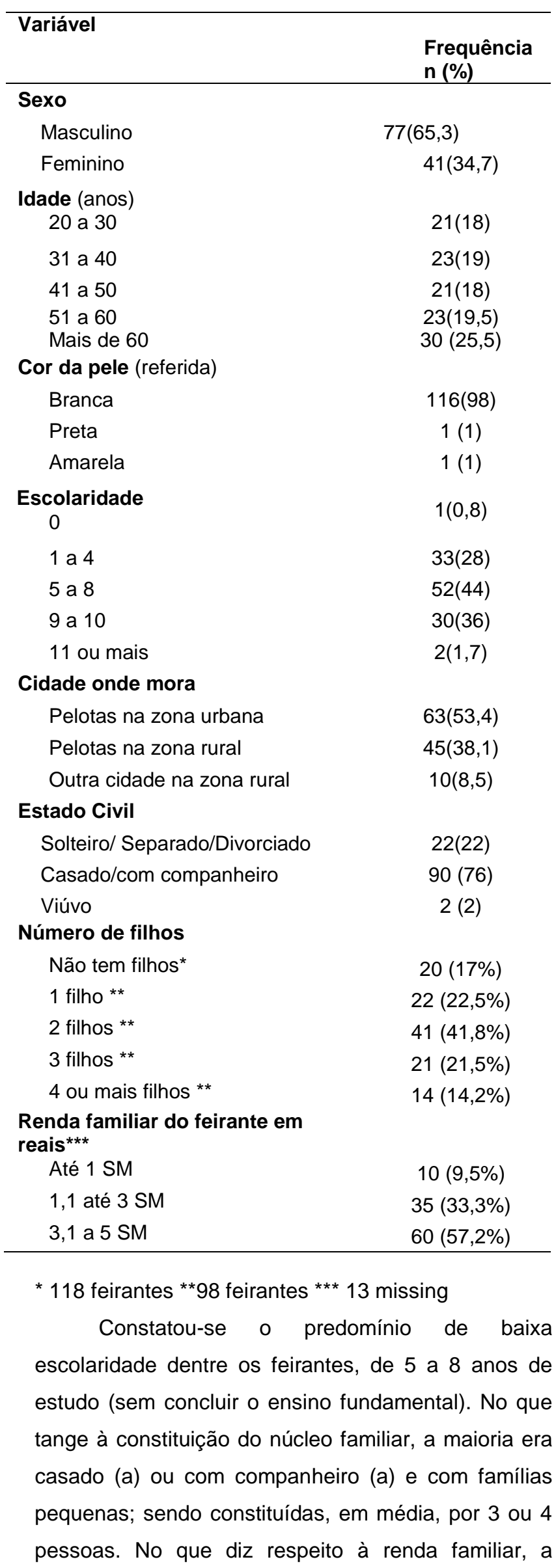


maioria dos feirantes que participaram da presente pesquisa (57\%) percebia de 3,1 a 5 salários mínimos.

A classificação dos feirantes, tomando como base a sua relação com a produção e comercialização das FLV, aproximadamente $40 \%$ dos feirantes eram somente revendedores, enquanto $23 \%$ comercializavam exclusivamente sua própria produção e, o restante (37\%), além de produzir para comercializar na feira, adquiriam FLV para revender (Tabela 3).

Tabela 3 - Caracterização dos locais de feiras-livre da cidade de Pelotas/2014

\begin{tabular}{lc}
\hline Variável & Frequência n (\%) \\
\hline Distribuição do número de & \\
bancas por grupo* & $69(55,2)$ \\
Grupo A & $19(15,2)$ \\
Grupo B & $17(13,6)$ \\
Grupo C & $9(7,2)$ \\
Grupo D & $2(1,6)$ \\
Grupo E & $2(1,6)$ \\
Grupo F & $7(5,6)$ \\
Orgânicos/Ecológicos & \\
Concentração de feiras por & \\
zona administrativa & \\
Zona 1 - Três Vendas & \\
Zona 3 - Fragata & $8(3,4)$ \\
Zona 4 - Centro & $8(6,8)$ \\
Zona 5 - Areal & $95(80,5)$ \\
Zona 6 - São Gonçalo & $3(2,5)$ \\
Zona 7 - Laranjal & $6(5,1)$ \\
Participação dos feirantes na & $2(1,7)$ \\
escolha do local da feira & $95(80,5)$ \\
Não & $23(19,5)$ \\
Sim & \\
Satisfação com o local & \\
Satisfeito & \\
\hline Não satisfeito & \\
\hline
\end{tabular}

* 125 feirantes encontrados

No período de aplicação do questionário, em torno de $60 \%$ dos feirantes (produtores) e $90 \%$ (produtores e revendedores) referiram que as FLV comercializadas provêm de produção convencional. A maioria dos revendedores (76\%) se abastecia na Associação de Comerciantes de Hortifrutigranjeiros de Pelotas, conhecida popularmente como CEASA, enquanto os outros $24 \%$ adquiriam os alimentos dos pequenos produtores da região.

Para analisar as características da produção e/ou revenda das FLV, buscou-se informações de cada um dos produtos. Do total de frutas comercializadas pôde-se observar que alimentos como banana (44\%), maçã (31\%), mamão (27\%), pera (25\%), uva (25\%) e manga (23\%) eram predominantemente revendidos, enquanto o morango (28\%), o melão (21\%) e o caqui (18\%) estavam sob responsabilidade produtiva dos feirantes (Tabela 4). As outras frutas tinham um percentual de produção e revenda semelhantes. 
Tabela 4- Características das frutas comercializados pelos feirantes, nas feiras-livres da cidade de Pelotas/2014

\begin{tabular}{lccc}
\hline \multicolumn{1}{c}{ Alimentos } & $\begin{array}{c}\text { Produzido e } \\
\text { revendido } \\
\text { N (\%) }\end{array}$ & $\begin{array}{c}\text { Somente } \\
\text { produzido }\end{array}$ & $\begin{array}{c}\text { Somente } \\
\text { revendido }\end{array}$ \\
\hline Ananá & $0(0,0)$ & $2(1,7)$ & $\mathbf{N}(\%)$ \\
Banana & $2(1,7)$ & $4(3,4)$ & $44(37,3)$ \\
Bergamota Poncan & $2(1,7)$ & $17(14,4)$ & $18(15,3)$ \\
Butiá & $0(0,0)$ & $2(1,7)$ & $0(0,0)$ \\
Cereja & $0(0,0)$ & $3(2,5)$ & $0(0,0)$ \\
Caqui & $1(1,0)$ & $21(18,0)$ & $10(8,0)$ \\
Figo & $0(0,0)$ & $1(0.8)$ & $1(0,8)$ \\
Goiaba & $2(1,7)$ & $20(17,0)$ & $11(9,3)$ \\
Kiwi & $0(0,0)$ & $0(0,0)$ & $2(1,7)$ \\
Laranja de suco & $1(0,8)$ & $23(19,5)$ & $34(28,8)$ \\
Laranja de Umbigo & $2(1,7)$ & $20(17,0)$ & $26(22)$ \\
Laranja do céu & $1(0,8)$ & $15(12,7)$ & $27(22,9)$ \\
Limão & $3(2,5)$ & $27(22,9)$ & $21(17,8)$ \\
Maça Argentina & $0(0,0)$ & $0(0,0)$ & $13(11,0)$ \\
Maça Fuji & $1(0,8)$ & $2(1,7)$ & $21(17,8)$ \\
Maça Gala & $0(0,0)$ & $8(6,8)$ & $36(30,5)$ \\
Mamão Formosa & $0(0,0)$ & $0(0,0)$ & $24(20,3)$ \\
Mamão Papaya & $0(0,0)$ & $0(0,0)$ & $32(27,1)$ \\
Manga & $1(0,8)$ & $1(0,8)$ & $27(22,9)$ \\
Maracujá & $1(0,8)$ & $8(6,8)$ & $11(9,3)$ \\
Melancia & $3(2,5)$ & $13(11,0)$ & $28(23,7)$ \\
Melão & $2(1,7)$ & $25(21,2)$ & $18(15,2)$ \\
Morango & $1(0,8)$ & $34(28,8)$ & $14(11,9)$ \\
Pêra & $0(0,0)$ & $5(4,2)$ & $29(24,6)$ \\
Uvêssego & $1(0,8)$ & $16(13,6)$ & $19(16,1)$ \\
Uva Itália & $9(7,6)$ & $29(24,6)$ \\
\hline & $1(0,8)$ & $1(0,8)$ & $10(8,5)$ \\
\hline
\end{tabular}

A maior parte dos legumes e verduras eram produzida pelos feirantes; como, por exemplo, no caso da alface (34\%), da abóbora (29\%), da beterraba (27\%), do milho (25\%), do almeirão (18\%) e da abobrinha (14\%) (Tabela 5). Porém, outros alimentos consumidos no dia a dia, como a batata rosa (34\%), a cebola (34\%) a cenoura (27\%), a batata branca (25\%) e o tomate $(23 \%)$ eram, na maior parte dos casos, revendidos.

Segundo relato dos feirantes, a maioria das frutas compradas na Associação e revendidas nas feiras são provenientes de outros estados do Brasil, o mamão, por exemplo, vem do Espírito Santo, a banana da Bahia, característica que é diferente e não ocorre dentre as FLV produzidas pelos feirantes ou compradas de pequenos produtores da região .

Tabela 5- Características dos legumes e verduras comercializados pelos feirantes nas feiras-livres da cidade de Pelotas/2014

\begin{tabular}{|c|c|c|c|}
\hline Alimentos & $\begin{array}{c}\text { Produzido e } \\
\text { revendido } \\
\text { N (\%) }\end{array}$ & $\begin{array}{c}\text { Somente } \\
\text { produzido } \\
\text { N (\%) }\end{array}$ & $\begin{array}{c}\text { Somente } \\
\text { revendido } \\
\mathbf{N}(\%)\end{array}$ \\
\hline Abóbora Japonesa & $3(2,6)$ & $34(28,8)$ & $22(18,7)$ \\
\hline Abóbora Moranga & $9(7,6)$ & $26(22,0)$ & $14(11,9)$ \\
\hline $\begin{array}{l}\text { Abobrinha } \\
\text { brasileira }\end{array}$ & $5(4,3)$ & $17(14,4)$ & $3(2,5)$ \\
\hline Agrião & $0(0,0)$ & $18(15,3)$ & $7(5,9)$ \\
\hline Aipim & $2(1,7)$ & $17(14,3)$ & $20(17,0)$ \\
\hline Alcachofra & $0(0,0)$ & $6(5,1)$ & $2(1,7)$ \\
\hline Alface & $7(5,9)$ & $40(33,9)$ & $10(8,4)$ \\
\hline Alho Poró & $0(0,0)$ & $10(8,5)$ & $26(22,0)$ \\
\hline Almeirão & $0(0,0)$ & $21(17,8)$ & $2(1,7)$ \\
\hline Araça & $0(0,0)$ & $1(0,8)$ & $0(0,0)$ \\
\hline Arpargo & $0(0,0)$ & $3(2,5)$ & $0(0,0)$ \\
\hline Batata Branca & $3(2,5)$ & $11(9,3 \%)$ & $30(25,4)$ \\
\hline Batata rosa & $1(1)$ & $13(11,0)$ & $40(34,0)$ \\
\hline Batata Doce & $3(2,5)$ & $28(23,7)$ & $28(23,7)$ \\
\hline Berinjela & $2(1,7)$ & $15(12,7)$ & $14(11,9)$ \\
\hline Beterraba & $5(4,2)$ & $32(27,1)$ & $19(16,1)$ \\
\hline Brócolis & $3(2,5)$ & $31(26,3)$ & $13(11,0)$ \\
\hline Cebola & $4(3,4)$ & $17(14,4)$ & $40(33,9)$ \\
\hline Cebolinha & $2(1,7)$ & $32(27,1)$ & $7(5,9)$ \\
\hline Cenoura & $5(4,2)$ & $26(22,0)$ & $32(27,1)$ \\
\hline Chicória & $0(0,0)$ & $7(6,0)$ & $0(0,0)$ \\
\hline Chuchu & $3(2,5)$ & $21(18,0)$ & $20(17)$ \\
\hline Couve & $7(6,0)$ & $41(35,0)$ & $12(10)$ \\
\hline Couve-manteiga & $5(4,2)$ & $30(25,4)$ & $10(8,5)$ \\
\hline Couve-Flor & $2(1,7)$ & $26(22,0)$ & $9(7,7)$ \\
\hline Espinafre & $3(2,5)$ & $27(22,9)$ & $9(7,6)$ \\
\hline Milho & $5(4,2)$ & $30(25,4)$ & $12(10,2)$ \\
\hline Mostarda & $2(1,7)$ & $36(30,5)$ & $11(9,3)$ \\
\hline Nabo & $2(1,7)$ & $23(19,5)$ & $6(5,1)$ \\
\hline Pepino & $4(3,4)$ & $28(23,7)$ & $16(13,6)$ \\
\hline Pimenta & $4(3,4)$ & $15(12,7)$ & $6(5,1)$ \\
\hline Pimentão & $5(4,3)$ & $30(25,4)$ & $32(27,1)$ \\
\hline Quiabo & $1(0,8)$ & $5(4,2)$ & $5(4,2)$ \\
\hline Rabanete & $3(2,5)$ & $22(18,7)$ & $10(8,5)$ \\
\hline
\end{tabular}




\begin{tabular}{lccc} 
Repolho & $2(1,7)$ & $24(20,3)$ & $16(13,6)$ \\
Rúcula & $5(4,2)$ & $34(28,8)$ & $5(4,2)$ \\
Salsa & $3(2,5)$ & $39(33)$ & $9(7,6)$ \\
Salsão & $0(0,0)$ & $9(7,6)$ & $2(1,7)$ \\
Tomate cereja & $7(5,9)$ & $22(18,6)$ & $15(12,7)$ \\
Tomate gaúcho & $4(3,4)$ & $26(22,0)$ & $33(28,0)$ \\
Tomate longa & $3(2,5)$ & $8(6,8)$ & $27(22,9)$ \\
Vagem & $6(5,1)$ & $30(25,4)$ & $19(16,1)$ \\
\hline
\end{tabular}

\section{Discussão}

De modo geral, as feiras podem ser classificadas em dois tipos: convencional e ecológica. Segundo os autores Assis e Romeiro (2002), na produção agrícola convencional há comprometimento da qualidade do solo, pois são realizadas "continuadas colheitas e remoção de restos de cultura"(ASSIS;ROMEIRO,2002,p.73). Este tipo de produção ocasiona a dependência de insumos como fertilizantes e agrotóxicos. Somente com a utilização destes produtos é possível alcançar uma alta produção e controlar as pragas. Ainda sobre a produção convencional, os autores referem que ocorre "uso abusivo de insumos agrícolas industrializados, dissipação do conhecimento tradicional e deterioração da base social de produção de alimentos" (ASSIS;ROMEIRO,2002,p.68).

Com relação à produção orgânica, toma-se como parâmetro a definição do Ministério da Agricultura (2014)

na agricultura orgânica não é permitido o uso de substâncias que coloquem em risco a saúde humana e o meio ambiente. Não são utilizados fertilizantes sintéticos solúveis, agrotóxicos e transgênicos. Para ser considerado orgânico, o produto tem que ser produzido em um ambiente de produção orgânica, onde se utiliza como base do processo produtivo os princípios agroecológicos que contemplam o uso responsável do solo, da água, do ar e dos demais recursos naturais, respeitando as relações sociais e culturais.

Este arranjo das feiras não se modificou muito ao longo do tempo. Um estudo realizado, em Pelotas, há nove anos, também verificou o predomínio de feiras livres no centro da cidade (GODOY, 2005). É importante esclarecer que o município de Pelotas não possui bairros cadastrados no Instituto Brasileiro de Geografia e Estatística (IBGE). Segundo o chefe da agência de Pelotas do IBGE, Rogério Krause, "essa classificação não atrapalha a vida da população, mas dificulta na hora de identificar a realidade social de determinada localidade"(SANTOS,2014).

Segundo a Lei No 5.490, de 24 de julho de 2008, que dispõe sobre a delimitação dos Distritos do Município de Pelotas e das Regiões Administrativas do seu Distrito Sede (Zona Urbana), existem nove distritos rurais e sete regiões administrativas que formam a zona urbana, a qual está dividida em: Fragata, Três Vendas, Centro, Areal, São Gonçalo, Laranjal e Barragem (PELOTAS, 2008). Dessa forma, a zona que concentra maior número de locais de feira compreende muitas ruas e diferentes realidades socioeconômicas.

Pode-se inferir, com isso, que há uma deficiência de feiras nas zonas afastadas do centro da cidade (regiões periféricas), o que tende a dificultar a aquisição e o consumo de FLV. Uma revisão bibliográfica, publicada em 2009, demonstrou que os moradores de regiões que têm melhor acesso a supermercados (locais que comercializam FLV) tendem a ter dietas mais saudáveis (Larson; Nelson, 2009)

A maior prevalência de homens já havia sido constatada em estudos realizados na Feira do Produtor de Passo Fundo (ROCHA et.al.,2010) e, em São Pedro do Sul (DA SILVA et. al.,2014) ambos no estado do Rio Grande do Sul. Uma maioria de feirantes, com idade entre 20 e 50 anos (55\%), já havia sido encontrada em Pelotas (GODOY, 2005), onde $56 \%$ dos feirantes convencionais tinham até 51 anos de idade. A faixa etária dos feirantes entre 30 e 55 anos também foi mais frequente em Passo Fundo/RS (ROCHA,et.al.,2010) e Maringá/PR (DEMENECK, et al,2011). A baixa escolaridade e a constituição familiar foram fator também encontrado em outros estudos com feirantes (GODOY,2005; ROCHA,et.al.,2010; DEMENECK, et. al.,2011). Com relação a renda familiar, os resultados dos demais estudos mostraram um predomínio de renda familiar de até um mil reais na cidade de Passo Fundo/RS (ROCHA,et.al.,2010)e, em 
Pelotas, uma renda inferior a quatro salários mínimos mensais (GOSOY,2005).

A maioria dos feirantes contava com o trabalho de até duas pessoas. Nesse contexto, esposas e filhos constituem a força de trabalho que, ao lado do feirante, responsabiliza-se pelo cultivo e venda dos alimentos. Tal processo demonstra a importância da mão de obra familiar, tanto na produção como na comercialização de FLV, e coloca a feira como um negócio de família.

Em estudo realizado, em 2005, na cidade de Pelotas (GODOY,2005), foi possível constatar que mais da metade dos feirantes (51\%) comprava tudo o que comercializava, $17 \%$ produzia a totalidade do que vendia na feira e o restante (32\%) produzia e comprava alimentos para comercializar. Ao comparar os dados do estudo realizado há quase dez anos com o atual, pode-se verificar que houve uma diminuição no número de feirantes que apenas compram e revendem os alimentos, e um aumento de seis pontos percentuais entre aqueles que produzem todas as FLV que comercializam.

Mesmo assim, os feirantes que são apenas revendedores continuam sendo a maioria nas feiras livres de Pelotas. Existem, nesse cenário, três tipos de feirantes: os que são somente produtores, aqueles que produzem e revendem, e outros que são apenas revendedores. Vale destacar que, nas feiras ecológicas, encontrou-se apenas os comerciantes do primeiro grupo, ou seja, exclusivamente produtores.

Percebe-se, assim, que o tipo de feira e de feirante podem determinar como as FLV estão sendo produzidas e comercializadas. O modelo de produção e de abastecimento reflete-se no consumo dos alimentos e, consequentemente, na saúde dos consumidores. Desde 2008, o Brasil carrega o título de maior consumidor mundial de agrotóxicos. Em análises realizadas pela Agência Nacional de Vigilância Sanitária (ANVISA), em 2011, alimentos como pimentão, morango, pepino, alface, cenoura, continham resíduos de agrotóxicos (ANVISA,2012).

Esse fato gera uma insegurança alimentar e nutricional, visto que esses agrotóxicos estão presentes em alimentos consumidos diariamente pelas pessoas. De acordo com a ANVISA, esses insumos químicos são: "ingredientes ativos com elevado grau de toxidade aguda comprovada e que causam problemas neurológicos, reprodutivos, desregulação hormonal e até câncer". Dessa forma, conforme apontado em publicação da Associação Brasileira de Saúde Coletiva(ABRASCO, 2012,p.23), mesmo que alguns dos ingredientes
ativos dos agrotóxicos, por seus
efeitos agudos, possam ser
classificados como medianamente
ou pouco tóxicos, não se pode
perder de vista os efeitos crônicos
que podem ocorrer meses, anos ou
até décadas após a exposição,
manifestando-se em várias doenças
como cânceres, malformação
congênita, distúrbios endócrinos,
neurológicos e mentais.

Além de prejudicar a saúde de consumidores e agricultores, o modo de produção baseado na utilização de agrotóxicos ocasiona o endividamento dos agricultores familiares e gera dependência em relação às empresas que vendem sementes e insumos, fatores também associados à SAN (MALUF;REIS,2013).

Diante desse processo, há que se pensar, portanto, nas vantagens que, principalmente as feiras destinadas aos produtores ecológicos, oportunizam para a SAN. Tais locais, além de compor um espaço de sociabilidade entre feirantes e fregueses, estimulam o desenvolvimento local. Constituem-se, assim, em circuitos curtos de comercialização, os quais, segundo Darolt e colaboradores (2013), promovem aproximação entre aquele que produz e aquele que consome o alimento. Os autores explicam que os "circuitos curtos" aumentam a autonomia com relação ao que produzir, vender e comprar. Isso sem deixar de considerar os impactos sociais e ambientais envolvidos nesse processo. Desse modo, as feiras livres contribuem para "a adoção de hábitos de consumo mais saudáveis e um melhor conhecimento das dificuldades na produção agrícola" (DAROLT,2013,p.12). Entende-se, com isso, que as feiras podem contribuir para estimular o consumo de FLV e, consequentemente, promover a SAN.

\section{Conclusões}

Ao concluir esse estudo foi possível perceber que a maioria das feiras está localizada no centro da 
cidade, dificultando a disponibilidade e acesso às FLV para a população que vive nos bairros. Vale ressaltar, também, que a maior parte dos feirantes não produzem os alimentos que comercializam e, aqueles que o fazem, utilizam a produção convencional. Além disso, evidencia-se uma preocupação quanto à continuidade das feiras. Fator destacado devido ao envelhecimento dos feirantes e a possível dificuldade em encontrar mão de obra para substituí-los no futuro. Essa situação se apresenta, sobretudo, por conta da nova composição familiar, com menor número de herdeiros.

No âmbito da saúde pública, entende-se que, para modificar as relações estabelecidas com a alimentação e aumentar a produção e comercialização de FLV, deve-se incentivar, por meio de políticas públicas, os agricultores familiares, principalmente de base ecológica, e as feiras-livres, para que dessa maneira se tenha uma reaproximação do consumidor com o produtor. Essa reconexão irá gerar práticas que se destinam ao empoderamento individual e coletivo, que devem estar voltadas para uma alimentação derivada de um sistema alimentar capaz de contribuir para a construção de uma sociedade mais justa e ambientalmente sustentável.

\section{Referências}

1 Agência Nacional de Vigilância Sanitária (ANVISA). Programa de análise de Resíduos de agrotóxicos em alimentos (PARA). Relatório complementar relativo à segunda etapa das análises de amostras coletadas em 2012. Agência Nacional de Vigilância Sanitária. Brasília; 2014 alimentar e nutricional. Ciência \& Saúde Coletiva. 2011;16 (1): p.187-199

2 Associação Brasileira de Saúde Coletiva. Dossiê ABRASCO - Um alerta sobre os impactos dos agrotóxicos na saúde. Parte 1 - Agrotóxicos, Segurança Alimentar e Nutricional e Saúde. Rio de Janeiro: ABRASCO; 2012

3 BRASIL, Decreto $\mathrm{n}^{\circ} 7.272$, de 25 de agosto de 2010. Regulamenta a Lei no 11.346 , de 15 de setembro de 2006, que cria o Sistema Nacional de Segurança Alimentar e Nutricional - SISAN com vistas a assegurar o direito humano à alimentação adequada, institui a Política Nacional de Segurança Alimentar e Nutricional - PNSAN, estabelece os parâmetros para a elaboração do Plano Nacional de Segurança Alimentar e Nutricional, e dá outras providências. [acesso 2014 dez 14]. Disponível em: http://presrepublica.jusbrasil.com.br/legislacao/1 024901/decreto-7272-10

$4 \quad$ BRASIL, Lei $n^{\circ}$ 11.346, de 15 de setembro de 2006. Cria o Sistema Nacional de Segurança Alimentar e Nutricional. SISAN com vistas em assegurar o direito Humano à alimentação adequada e dá outras providências. Diário Oficial [da] República Federativa do Brasil, Brasília, DF, 15 set. 2006

5 BRASIL. Ministério da Saúde. Coordenação Geral da Política de Alimentação e Nutrição. Ações de Incentivo ao Consumo de Frutas e Hortaliças do Governo Brasileiro. Brasília, 2009.

6 Conselho de Segurança Alimentar e Nutricional. A Segurança Alimentar e Nutricional e o Direito Humano à Alimentação Adequada no Brasil Realização - Indicadores e Monitoramento - da constituição de 1988 aos dias atuais. Brasília, 2010.

7 Contreras J, Gracia M. Alimentação, sociedade e cultura. Rio de janeiro: Editora Fiocruz; 2011

8 Da Silva GP. et al. Perfil e percepções dos feirantes em relação a feira livre dos municípios de São Pedro do Sul (RS) e Santo Augusto (RS). Revista Monografias Ambientais, 2014, 13(2): 3203-3212

9 Darolt MR. A diversidade dos circuitos curtos de alimentos ecológicos: ensinamentosdo caso brasileiro e francês. Agriculturas. 2013; 10(2). p.813 
De Assis RL, Romeiro AR. Agroecologia e agricultura orgânica: controvérsias e tendências. Desenvolvimento e meio ambiente. 2002; 6: p. $67-80$

Demeneck MT. et al. Perfil sócio econômico de feirantes que comercializam hortaliças na feira do produtor no Município de Maringá- PR, 2011. Maringá. Anais, Eletrônico CESUMAR: Centro Universitário de Maringá. Acesso em: 21 jan. 2014

Godoy WI. As feiras-livres de Pelotas, RS: Estudo sobre a dimensão socioeconômica de um sistema local de comercialização [tese] Pelotas (RS).Faculdade de Agronomia Eliseu Maciel. Universidade Federal de Pelotas; 2005

Larson NI, Story MT, Nelson MC. Neighborhood environments: Disparities in access to healthy foods in the U.S. American Journal of Preventive Medicine. 2009;36(1):74-81

Maluf R, Reis MC. Segurança Alimentar e Nutricional na Perspectiva Sistêmica. In: Rocha C. Segurança Alimentar e Nutricional: perspectivas, aprendizados e desafios para as políticas públicas. Rio de Janeiro: Fiocruz, 2013. p. $43-68$

Maluf RS, Menezes F. Produção de alimentos e eqüidade social. Caderno "Segurança Alimentar" 2000.

Maluf RS. Segurança alimentar e nutricional. Petrópolis - Rio de janeiro: Vozes; 2009

Ministério da Agricultura. O que são alimentos orgânicos. [acesso em 29 dez. 2014]. Disponível em:

http://www.agricultura.gov.br/desenvolvimentosu stentavel/organicos/o-que-e-agricultura-organica
Panelli-Martins BE, Santos SMC, Assis AMO. Segurança Alimentar e Nutricional: desenvolvimento de indicadores e experimentação em um município da Bahia, Brasil. Rev. Nutr.,Campinas. 2008; 21(suplemento): p.65-81

PELOTAS. Lei No 5.490, de 24 de julho de 2008. Dispõe sobre a delimitação dos Distritos do Município de Pelotas e das Regiões Administrativas do seu Distrito Sede (Zona Urbana), e dá outras providências. [acesso 2014 dez 02]. Disponível em: http://www.pelotas.rs.gov.br/interesse legislacao /leis/2008/lei 5490.pdf

21 Pinheiro ARO, Gentil PC. A Iniciativa de Incentivo ao consumo de Frutas, Verduras e Legumes $(f, I \& v)$ :uma estratégia para abordagem intersetorial no contexto da Segurança Alimentar e Nutricional (CONSEA - Brasil). Brasília, 2005

Rocha HC, Costa C, Castoldi FL, Cecchetti D, Calvete E , Lodi BS. Perfil socioeconômico dos feirantes e consumidores da Feira do Produtor de Passo Fundo, RS. Ciência Rural. 2010; 40 (12) Santos D. Pelotas: a cidade sem bairros [Internet]. [acesso 2014 nov 22]. Disponível em: http://www.diariopopular.com.br/tudo/index.php? $\underline{\mathrm{n} \text { sistema }=3056 \& i d \text { noticia }=\text { ODQwNDA }=\text { \&id ar }}$ $\underline{\mathrm{e} a=\mathrm{Mg}}$ 